\title{
What are the psychological correlates of perceived adverse food reactions?
}

\author{
Saliha Mahmood \\ From Food Allergy and Anaphylaxis Meeting 2011 \\ Venice, Italy. 17-19 February 2011
}

\section{Background}

Population studies suggest that around $20.4 \%$ of the UK population consider themselves affected by perceived adverse food reactions. However, formal testing reveals that only $1.4 \%$ are truly affected by either food allergy and/or food intolerance. The reason for this large discrepancy has been the subject of very few studies. This study aims to identify the prevalence of perceived adverse food reactions (PAFR) in a healthy population, and to evaluate any relationship between PAFR and psychological factors such as disordered eating, subjective stress and modern health worries.

\section{Methods}

A self report questionnaire was completed by 194 medical or physiotherapy students. Overall response rate was $80.8 \%$. The questionnaire identified individuals with a PAFR and used validated measures of bulimic symptomatology (Bulimic Inventory Test Edinburgh), subjective stress (Perceived Stress Scale) and modern health worries (Modern Health Worries Scale).

\section{Results}

The prevalence of PAFR was found to be $28.4 \%$. Female and physiotherapy students were found to be more likely to report food reactions than male or medical students. Those participants who had a PAFR demonstrated higher levels of bulimic symptomatology $(\mathrm{p}<0.0001)$ and higher levels of subjective stress than controls $(\mathrm{p}<0.05)$. Levels of modern health worries did not differ significantly in participants with and without a PAFR.

\section{Conclusion}

This study has made progress in validating a questionnaire to measure adverse food reactions. This

\footnotetext{
Kings College London, Ickehnam, UK
}

() 2011 Mahmood; licensee BioMed Central Ltd. This is an open access article distributed under the terms of the Creative Commons Attribution License (http://creativecommons.org/licenses/by/2.0), which permits unrestricted use, distribution, and reproduction in any medium, provided the original work is properly cited. instrument may be of benefit to future researchers and clinicians alike. This study suggests that PAFR's are related to bulimic patterns of disordered eating and perceived stress levels. In light of this finding, healthcare professionals such as dieticians may find benefit in screening for bulimia nervosa in individuals presenting with a PAFR: particularly young, stressed females who may use adverse food reactions to justify maladaptive eating.

Published: 12 August 2011

\section{doi:10.1186/2045-7022-1-S1-P116}

Cite this article as: Mahmood: What are the psychological correlates of perceived adverse food reactions? Clinical and Translational Allergy 20111 (Suppl 1):P116.
Submit your next manuscript to BioMed Central and take full advantage of:

- Convenient online submission

- Thorough peer review

- No space constraints or color figure charges

- Immediate publication on acceptance

- Inclusion in PubMed, CAS, Scopus and Google Scholar

- Research which is freely available for redistribution

\section{Biomed Central}

